\title{
Occupational radiation exposures for medical workers in Pakistan - An overview
}

\author{
Misbah AHMAD ${ }^{1, a}$, Iftkhar AHMAD ${ }^{1}$, Aakif Ullah KHAN ${ }^{1}$, Amin Ali KHAN ${ }^{1}$, Kamran Ali SHAH ${ }^{1}$, Jamil AHMAD \\ ${ }^{\prime}$ Institute of Radiotherapy and Nuclear Medicine (IRNUM), Peshawar, KP Pakistan \\ ${ }^{2}$ Department of Chemistry, Hazara University, Mansehra 21120, KP, Pakistan \\ ${ }^{a}$ E-mail address: mabagh@gmail.com
}

(received 24 October 2019; accepted 30 December 2019)

\begin{abstract}
The imperative use of ionizing radiation in medicine causes the inevitable occupational exposure of the medical workers during the course of routine duties. The magnitude of health risk due to such radiation exposures has been described in terms of occupational radiation doses. In this context, it is obligatory to monitor, measure and document the radiation dose of occupationally exposed medical workers. This study aims to review the whole-body occupational radiation exposures of medical workers in Pakistan. Specifically, online literature published during 2000-2018 was reviewed for the occupational radiation exposures of Pakistani medical workers. Analysis of the extracted personal dosimetry data revealed that the total number of monitored medical occupational workers was 26046. The range of total cumulative and annual average effective doses was 94-15785 Person-mSv and 0.66-7.37 mSv, respectively. A significant number of the workers $(25477$; $~ 98 \%)$ received an annual dose below $5 \mathrm{mSv}$, while only 18 workers received an occupational exposure exceeding the annual dose limit of $20 \mathrm{mSv}$. It is expected that this study will provide a useful reference for evaluating and improving radiation protection and safety policies in the country.
\end{abstract}

Key words: occupational exposure; radiation protection; effective dose; dose limits.

\section{Introduction}

Occupational radiation exposures are defined as the exposure of workers to ionizing radiation as a result of their work in the radiation fields, both natural and man-made, except for exposures from the standards, practices or sources exempted by standards [1-2]. Occupational radiation exposure of the workers during the course of routine duties is inevitable and pose an inherent health risk if ample efforts for protection are not ensured [3-5]. In this context, one of the most important aspects of radiation protection is to monitor the occupational radiation exposure of each individual worker, primarily to keep the occupational workers below the known thresholds for the manifestation of deterministic effects and to minimize the probability of stochastic hazards of ionizing radiations. Moreover, exposure monitoring of occupational workers also provides information regarding the capability and effectiveness of the radiation protection program. In addition, individual monitoring program also aims to reveal compliance with maximum permissible dose limit as required by the national regulations and international recommendations and standards [6-8].

Among others, ionizing radiations are extensively used in medicine, both for diagnostic and therapeutic purposes [9]. Specifically, many medical diagnostic applications exploit ionizing radiations either external or internal to the patient in the form of diagnostic radiology or nuclear medicine, respectively. Likewise, the medical therapeutic applications of ionizing radiations are also conventionally classified into two categories- based on whether the source of radiation is placed external (i.e., teletherapy) or internal (i.e., brachytherapy and internal nuclear medicine) to the patient [2,9]. All these radiation-based medical procedures are carried out with the help of specially trained medical staff- the occupational workers. It is obvious that this subset of medical staff (i.e., the occupational workers) is at elevated risk of radiation hazards which needs to be appropriately assessed in terms of monitoring the radiation dose received by each individual worker.

Medical institutes/centers in Pakistan that exercise radiationbased practices comprise one or more of the following mainstream departments; diagnostic radiology (DR) department which offers conventional diagnostic facilities such as X-ray unit, computed tomography, mammography, fluoroscopy, etc. Nuclear medicine (NM) departments make use of unsealed radionuclides (e.g., Tc-99m, I-131, etc.) for both diagnostic and therapeutic purposes. Radioimmunoassay (RIA) is also considered an allied part of NM departments. In addition, few NM departments are also equipped with

(C) 2020 Misbah Ahmad, Iftkhar Ahmad, Aakif Ullah Khan, Amin Ali Khan, Kamran Ali Shah, Jamil Ahmad. This is an open access article licensed under the Creative Commons Attribution-NonCommercial-NoDerivs License (http://creativecommons.org/licenses/by-nc-nd/3.0/). 
cyclotron and ${ }^{18}$ fluorodeoxyglucose positron emission tomography ( ${ }^{18}$ FDG PET) systems. Radiotherapy (RT) departments comprise of medical linear accelerators, cobalt-60 teletherapy and brachytherapy units. The medical workers of the above-mentioned departments are occupationally exposed to ionizing radiations and thereby their radiation doses are monitored and documented, as per the guidance and obligations of national (i.e., Pakistan Nuclear Regulatory Authority; PNRA) [10] and international (i.e., International Commission on Radiological Protection; ICRP and International Atomic Energy Agency; IAEA) agencies [11-17].

Previously, a large cohort of studies focusing on the assessment of occupational exposed medical worker has been reported from around the globe, including Pakistan [6-9,18-35]. These studies, in particular those reported from Pakistan, are scattered, discuss/ focus on different dosimetry indices and non-overlapping study periods, all confounding a meaningful analysis and comparison. In this context, a comprehensive compilation and objective analysis of the studies reporting on the occupational exposure of Pakistani medical workers seems of potential importance. Specifically, such analysis will not only facilitate insights into the adherence with the obligatory requirements but also culminate a cross-platform comparison of our personal dosimetry patterns with other studies. With these objectives, we start with a brief history and evolution of radiation protection in Pakistan, followed by a comprehensive online literature review aimed at the occupational radiation exposure of Pakistani medical workers. Dosimetry analysis of the workers has also been based on the respective departments. Finally, the compiled dosimetry data has been compared to similar international studies. This work will provide a useful reference for the assessment and up-gradation of radiation protection and safety policies.

\section{Radiation Protection in Pakistan; History and Evolution}

The promulgation of the Pakistan Atomic Energy Commission (PAEC) ordinance in 1965 introduced the first comprehensive layout of the radiation protection program for occupational workers in Pakistan [36]. To further improve the radiation protection culture in the country, the first statutory structure, named as Directorate of Nuclear Safety and Radiation Protection (DNSRP) was established in 1984. Afterward, Pakistan signed the International Convention on Nuclear Safety (ICNS) in 1994; composition of an independent nuclear regulatory body, responsible for the legislative and regulatory framework (and its implementation) governing nuclear power and the use of ionizing radiation in the country, was among the various commitments as imposed by ICNS. To this end, Pakistan Nuclear Regulatory Board (PNRB) was established as a transitory measure, with the mandate to separate the regulatory functions from the promotional aspects of the nuclear program. In 2001, the Pakistan Nuclear Regulatory
Authority ordinance No.III was promulgated; consequently, the PNRA was established as a competent and independent body for the regulation of nuclear safety and radiation protection in the country [37]. Overall, these initiatives taken by the Government of Pakistan were aimed to regulate, safeguard, and monitor the activities pertaining to the use of ionizing radiations in the country.

Presently, PNRA is working as an independent regulatory body with the mission to protect radiation workers, the general public and the environment from the harmful effects of ionizing radiation by formulating and implementing effective regulations. In this perspective, PNRA has issued several regulations and guides as part of its regulatory framework on radiation protection for the management of/reducing occupational exposures. In particular, PNRA regulation PAK/904, focused on the safety of occupational workers, adopted the maximum permissible occupational dose limit as per the recommendations of IAEA and ICRP. Specifically, the maximum annual effective dose of occupational workers was set at $20 \mathrm{mSv}$ averaged over a period of 5 years, with a stipulation that the individual dose should not exceed $50 \mathrm{mSv}$ in any single year [10]. PNRA monitor all radiation-based facilities (including medical centers) in the country to ensure adherence to its regulations.

\section{Methods}

\section{Online Literature Search}

To compile the relevant data, a thorough search of the online literature pertaining to the studies published in peer-reviewed journals on the subject of occupational exposure in medical practices in Pakistan was conducted. Specifically, the online search was started with the relevant key words such as radiation protection, occupational exposure, effective dose, ionizing radiation, dose limit, etc. and was subsequently segregated to Pakistan. Four online international bibliographic databases i.e., PubMed, EMBASE, Scopus and Google Scholar were searched. Moreover, for relevant studies published in national research journals, the search was conducted using the "PakMediNet" database. The search was restricted to studies published from January 2000 to December 2018 in the English literature only. The references cited in each useful publication were traced for the identification of other relevant publications.

\section{Study Selection Procedure and Criteria}

The selection of relevant studies was performed as per the following procedure: One reviewer (MA) carried out the initial searches and identified the studies. In the case of duplicate studies, only one was included. Two independent reviewers (IA and $\mathrm{AK}$ ) screened the title and abstract of all the identified studies to determine their relevance towards the objectives of the present work. The inclusion criteria were: English language literature published during 2000-2018, focused on the assessment and analysis of the whole body radiation exposure 
of medical workers in Pakistan. Disagreement, if any, regarding the inclusion/exclusion of a given study in this work was resolved through discussion between the two reviewers.

\section{Data Extraction from Included Studies and the Analysis}

Data extraction from the included studies was performed by another reviewer (KAS) and verified by two independent reviewers (AAK and JA). The following data were extracted for each study: author identification, study duration, publication year, workers monitored, department of the worker, annual effective dose, maximum and minimum occupational dose and distribution of workers in various effective dose intervals. From this data, we calculated total collective effective dose (TCED) and annual average effective doses (AAED) using the following relations:

TCED $=\sum_{i}^{N} E_{i}$

Eq. 1

$\mathrm{AAED}=\frac{T C E D}{N}$

Eq. 2

where $E_{i}$ is the annual effective dose received by the ith worker and $\mathrm{N}$ is the total number of occupational workers in each study. Discrepancies in opinion about a data point were reviewed, and the consensus was achieved through discussion. Moreover, the primary authors of the studies with insufficient information were contacted, whenever possible, to acquire and verify the data. All data and statistical analyses were performed in Microsoft Excel.

\section{Results}

The initial search of the five online databases (i.e., PubMed, EMBASE, Scopus, Google Scholar and PakMediNet) identified 3178 studies that were related to radiation exposures. Of them, 1019 studies appeared in more than one database and were thereby considered only once. Next, the titles and abstracts of the remaining 2159 studies were thoroughly analyzed to select the studies focused on the occupational exposures only; 2071 studies were screened out in this step due to the fact that these studies did not report on occupational exposures. Out of the remaining 88 full-text articles, 46 studies were not related to occupational medical exposure, 31 studies did not assessed radiation doses for workers, 1 study reported insufficient data for extraction and the data presented in 2 studies was almost identical (and thereby considered only once). Finally, only 9 studies fulfilled the complete inclusion criteria and were included in the review. A flow chart diagram illustrating the major steps of this online literature review and segregation process is shown in Figure 1.

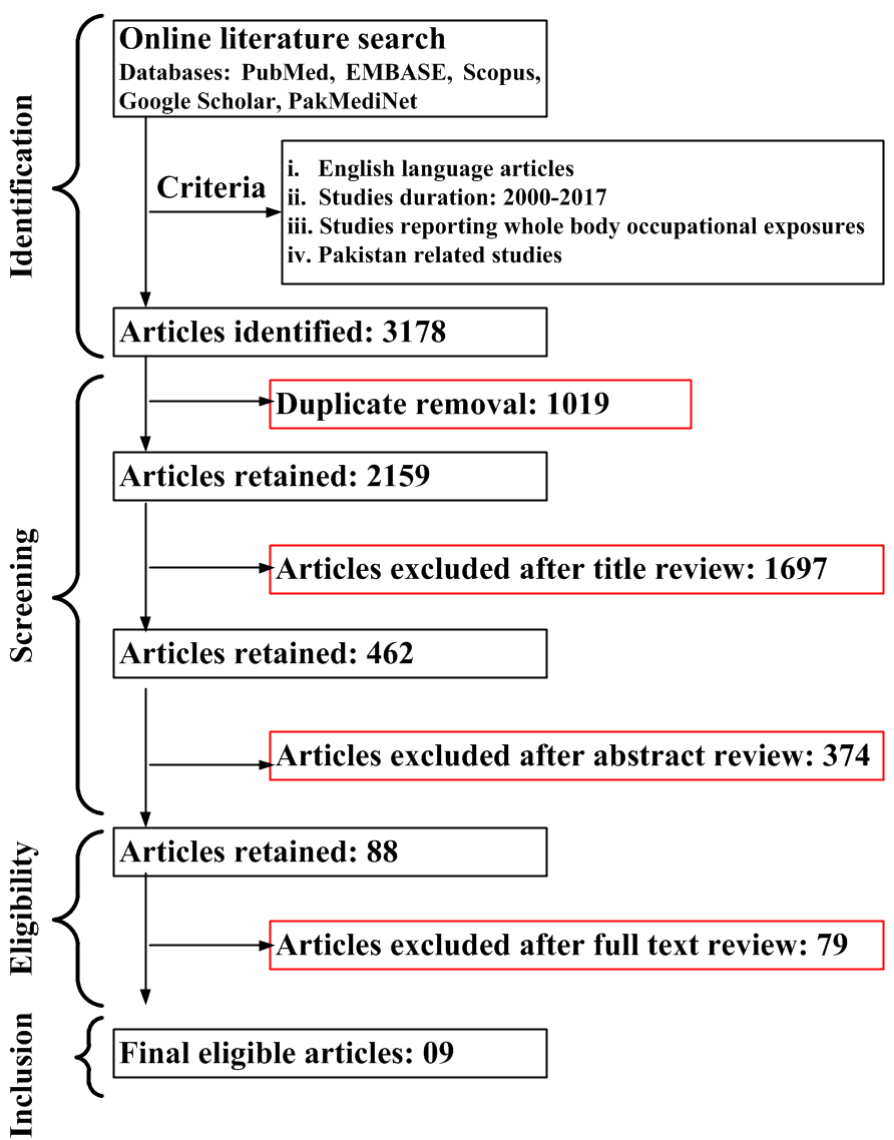

Figure 1. Summary of the online literature review process. The online literature search via five bibliographic databases (i.e., PubMed, EMBASE, Scopus, Google Scholar and PakMediNet) identified 3178 studies. The number of studies that appeared in more than one database was 1019; screening the title/abstract showed that $1697 / 374$ studies did not reported on occupational exposures, 46/31 studies were not related to occupational medical exposure/assessed radiation doses for workers, 01 study reported insufficient data and 01 study were almost identical to the other study. Excluding all these studies, 09 studies finally qualified the complete criteria for inclusion in the review.

The overall summary of the studies included $(n=09)$ in this work is presented in Table 1. The total number of monitored medical occupational workers was 26046, with the sample size (i.e., the number of workers) of individual studies ranged from 52 to 13237. The range of TCED (Table 1, column 4) was 9415785 Person-mSv, while that of AAED (Table 1, column 5) was 0.66-7.37 mSv, as calculated with Equation 1 and 2, respectively. It is noteworthy that, for easy comparison, both these dosimetry metrics were normalized for the duration of the study and the number of workers monitored.

The level of radiation dose received by occupational workers is typically correlated with the nature of the radiation field pertaining to the working environment. To this end, we also analyzed the level of radiation doses of the individual workers based on their working departments such as DR, RT, NM, ${ }^{18}$ FDG PET and RIA. The department-wise radiation doses of the workers are summarized in Table 2. 
Table 1. The overall summary of annual effective dose and TCED for the occupationally exposed medical workers (2000-2018).

\begin{tabular}{|c|c|c|c|c|c|c|}
\hline \multirow{2}{*}{ Reference } & \multirow{2}{*}{ Study period } & \multirow{2}{*}{ Workers monitored } & \multirow{2}{*}{$\begin{array}{c}\text { TCED } \\
(\text { Person-mSv) }\end{array}$} & \multicolumn{3}{|c|}{ Annual effective dose (mSv) } \\
\hline & & & & Average & Range & SD \\
\hline Jabeen et al. [2] & $2003-07$ & 11003 & 15785 & 1.43 & $1.23-1.65$ & 0.16 \\
\hline Rahim et al. [38] & $2000-08$ & 442 & 718 & 1.60 & $1.03-2.11$ & 0.36 \\
\hline Masood et al. [39] & $2007-11$ & 304 & 258 & 0.84 & $0.43-1.43$ & 0.4 \\
\hline Memon et al. [40] & $2007-11$ & 175 & 238 & 1.36 & -------- & \\
\hline Zafar et al. [41] & $2003-12$ & 13237 & 8800 & 0.66 & $0.48-0.85$ & 0.11 \\
\hline Younas et al. [42] & $2009-13$ & 95 & 700 & 7.37 & $2.4-9.0$ & 2.35 \\
\hline Ghadi et al. [43] & $2000-13$ & 378 & 609 & 1.61 & $0.66-2.08$ & 0.37 \\
\hline Razzaq et al. [44] & 2013-14 & 52 & 94 & 1.81 & $1.65-1.97$ & 0.23 \\
\hline Ahmad et al. [45] & $2009-16$ & 360 & 469 & 1.30 & $1.14-1.50$ & 0.12 \\
\hline
\end{tabular}

TCED = Total Collective Effective Dose; SD = Standard Deviation;

Table 2. The distribution of occupationally exposed medical workers from different departments in various AAED intervals..

\begin{tabular}{|c|c|c|c|c|c|c|c|}
\hline \multirow{2}{*}{ Reference } & \multirow{2}{*}{ Department } & \multirow{2}{*}{ No. of Workers } & \multirow{2}{*}{ AAED $(\mathbf{m S v})$} & \multicolumn{4}{|c|}{ AAED intervals (mSv) } \\
\hline & & & & $<5$ & $5-9.99$ & $10-20$ & $>20$ \\
\hline \multirow{3}{*}{ Jabeenet et al. [2] } & RT & 1833 & 1.17 & 1819 & 10 & 4 & ----- \\
\hline & NM & 2008 & 1.55 & 1947 & 59 & 1 & 1 \\
\hline & DR & 7162 & 1.47 & 6897 & 197 & 54 & 14 \\
\hline \multirow{4}{*}{ Rahim et al. [38] } & RT & 217 & 1.32 & 211 & 4 & 2 & ------ \\
\hline & NM & 124 & 2.15 & 120 & 1 & ----- & 3 \\
\hline & DR & 45 & 1.65 & 45 & ------ & ----- & ----- \\
\hline & RIA & 56 & 1.40 & 56 & ------ & ------ & ------ \\
\hline \multirow{3}{*}{ Masood et al. [39] } & RT & 137 & 0.88 & 134 & 3 & ----- & ----- \\
\hline & $\mathrm{NM}$ & 132 & 1.12 & 129 & 3 & ----- & ----- \\
\hline & DR & 35 & 0.52 & 35 & ------ & ----- & ----- \\
\hline \multirow{4}{*}{ Memon et al. [40] } & RT & 70 & 1.15 & 70 & ----- & ----- & ----- \\
\hline & NM & 65 & 1.69 & 63 & 2 & ------ & ------ \\
\hline & DR & 20 & 1.49 & 20 & ------ & ------ & ----- \\
\hline & RIA & 20 & 0.87 & 20 & ----- & ----- & ----- \\
\hline \multirow{3}{*}{ Zafar et al. [41] } & RT & 4570 & 0.70 & 4535 & 35 & ------ & ------ \\
\hline & $\mathrm{NM}$ & 5854 & 0.63 & 5799 & 55 & ----- & ----- \\
\hline & DR & 2813 & 0.68 & 2782 & 31 & ----- & ----- \\
\hline \multirow[t]{2}{*}{ Younas et al. [42] } & ${ }^{18}$ FDG PET & 95 & 7.37 & 5 & 90 & ----- & ----- \\
\hline & RT & 206 & 1.43 & 206 & ----- & ----- & ----- \\
\hline \multirow[t]{3}{*}{ Ghadi et al. [43] } & NM & 148 & 1.88 & 148 & ----- & ------ & ----- \\
\hline & DR & 24 & 1.49 & 24 & ----- & ----- & ----- \\
\hline & $\mathrm{RT}$ & 15 & 1.67 & 15 & ------ & ------ & ----- \\
\hline \multirow[t]{3}{*}{ Razzaq et al. [44] } & NM & 15 & 1.97 & 15 & ------ & ------ & ------ \\
\hline & DR & 22 & 1.79 & 22 & ------ & ------ & ------ \\
\hline & RT & 180 & 1.23 & 180 & ------ & ----- & ----- \\
\hline \multirow[t]{2}{*}{ Ahmad et al. [45] } & NM & 147 & 1.39 & 147 & ----- & ----- & ----- \\
\hline & DR & 33 & 1.30 & 33 & ------ & ----- & ------ \\
\hline
\end{tabular}

AAED = Average Annual Effective Dose; RT = Radiotherapy; NM = Nuclear Medicine; DR = Diagnostic Radiology; RIA = Radioimmunoassay;

${ }^{18}$ FDG PET $={ }^{18}$ fluorodeoxyglucose Positron Emission Tomography 
AAED comparison among various departments illustrated that the highest radiation doses were received by the workers of ${ }^{18}$ FDG PET followed by NM and DR. To facilitate an easy comparison, the received annual effective doses were categorized in pre-defined intervals (i.e., < 5, 5-9.99, 10-20 and $>20 \mathrm{mSv}$ ) and presented in Figure 2. Distribution of the workers in these dose intervals revealed that a significant number of the workers (i.e., 25477; $98 \%$ ) received an annual dose below $5 \mathrm{mSv}$. Further, analysis of the data showed that 18 workers received occupational exposure exceeding the annual dose limit of $20 \mathrm{mSv}$ (Table 2); of them, 14 workers were from DR department while 4 workers were from of NM department. However, none of the workers received the maximum annual dose limit of $50 \mathrm{mSv}$ in any single year and therefore no overexposure case has been reported from Pakistan.

The number of occupationally exposed workers in different departments is depicted in Figure 3. It may be noted that DR department engaged the largest number of workers (i.e., 10154; 39\%) monitored, followed by NM $(8493 ; 32.6 \%)$ and RT $(7228 ; 27.75 \%)$. The minimum number of workers $(76 ; 0.29 \%)$ was reported in RIA. It is noteworthy that the occupational workers $(95 ; 0.36 \%)$ of ${ }^{18}$ FDG PET were placed in a separate category due to its distinctive nature.

\section{Discussion}

The assessment of radiation doses to occupationally exposed medical workers is an obligation through national and international regulations. In Pakistan, like other IAEA member countries, the occupational doses of all registered medical workers are thereby measured with the aim to maintain the dose record and ensure regulatory compliance. For this purpose, the film badge dosimetry (FBD) technique has been implemented in all medical institutes/ centers offering radiation-based facilities $[2,38-41,43,45]$. Specifically, it is compulsory for each radiation worker to wear the film badge (on the upper torso) during the working hours to monitor the whole-body radiation exposure. This FBD-based approach for personal monitoring is capable of recording exposures ranging from $0.1 \mathrm{mSv}$ to $18 \mathrm{~Sv}$. Albeit FBD technique is simple, economical and provides permanent dose records in the form of processed films, its minimum radiation detectable level $(\mathrm{MDL}=0.1 \mathrm{mSv})$ seems a major disadvantage. However, this did not limit the ability to monitor the radiation doses of individual workers using FBD approach. Alternatively, some of the medical institutes in Pakistan are switching from FBD to thermoluminescence dosimetry (TLD) systems.

Variation in the reported values of radiation doses for occupationally exposed medical workers through individual monitoring in Pakistan has been analyzed in this review. The range of AAED for all workers was $0.66-7.37 \mathrm{mSv}$; the highest AAED of $7.37 \mathrm{mSv}$ was reported for 18FDG PET workers [42]. All other studies included in this review reported AAED values of less than $2 \mathrm{mSv}$ (Table 1).

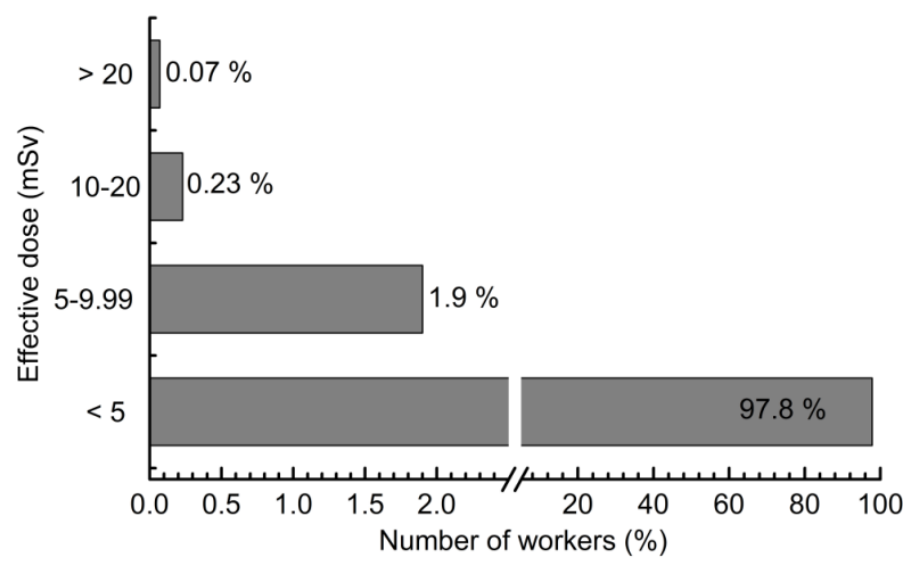

Figure 2. The distribution of occupationally exposed medical workers in various AAED intervals.

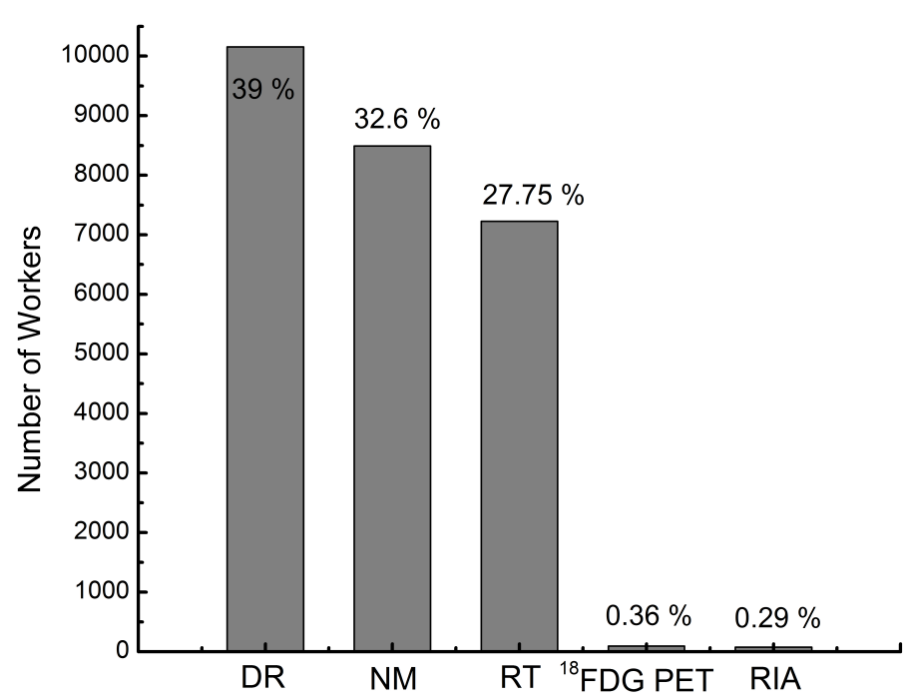

Figure 3. The department-wise distribution of occupationally exposed medical workers.

It may be prudent to conclude that these observations are indicative of the efficient and effective implementation of protective measures against radiation exposure in Pakistan. It is also noteworthy that some studies have revealed a declining trend in the AAED values over time, though the frequency of radiation-based practices has increased; several factors may have contributed towards this tendency. In particular, extensive educational programs aimed at improving the skills of radiation workers and stimulating awareness has been given special considerations in the recent years, which ultimately manifested in the better practices of radiation protection in the clinics.

The distribution of AAED values was skewed towards the low dose range, with a significantly higher number of the workers (i.e., 25477; $29 \%$ ) receiving an annual dose of less than $5 \mathrm{mSv}$ (Figure 3). These results are consistent with other similar international studies. For instance, Valuckas et al. reported that $97.4 \%$ of the Lithuanian medical radiation workers received AAED of less than $5 \mathrm{mSv}$ during the study period of 1991-2003 (22). Likewise, analysis of AAED values for the medical radiation workers of Portugal, Kenya, and 
Poland also demonstrated that $97.8 \%, 98 \%$, and $97 \%$ of worker received radiation doses below $5 \mathrm{mSv}$, respectively [25,46,47]. Review and analysis of the data showed that 18 workers received an occupational exposure exceeding the annual dose limit of $20 \mathrm{mSv}$ (Table 2); however, no worker received the maximum annual dose limit of $50 \mathrm{mSv}$ in any single year. To appropriately investigate and address such overexposures, each medical institute/ center follows a slightly different indigenous action plan. In general, each institute had established an action level (typically $50 \%$ of the regulatory annual dose limit; i.e., 10 $\mathrm{mSv}$ ) where annual doses higher than $10 \mathrm{mSv}$ are probed by the local radiation protection committee to explore and document the reasons. Alternatively, annual doses higher than $20 \mathrm{mSv}$ are interrogated by both the local radiation protection committee and the national regulatory body (i.e., PNRA) to explore the possible cause(s). Overexposure records that are not found factual in such investigation are discarded. That said, the studies reporting annual doses higher than $20 \mathrm{mSv}$ did not discuss their specific reasons/action plans. Nevertheless, the implementation of extensive educational programs for the medical staff will likely reduce the occupational radiation exposure, potentially minimizing the chances for such overexposures [45].

Comparison of the occupational doses of various radiation workers illustrated that the highest AAED was received by the workers involved in performing ${ }^{18} \mathrm{FDG}$ PET studies (i.e., AAED $=7.37$ vs. $<2 \mathrm{mSv}$; Table 1) [42]. In the context of relatively higher occupation doses, the rapid growth of ${ }^{18}$ FDG PET facilities in Pakistan demands objective education of the workers engaged in ${ }^{18}$ FDG PET through training and hands-on workshops towards strengthening the radiation protection and safety. In addition, albeit these AAED values appear consistent with the previous literature, a one to one comparison with other similar reports is difficult because of the variability in technique, protocols, image acquisition times, injected radioactivity and workload, among others [48-57]. More specifically, the AAED values for the workers of ${ }^{18}$ FDG PET have been previously reported to vary in the range of 1.93-12 $\mathrm{mSv}$. The higher radiation exposure in ${ }^{18}$ FDG PET procedures has been attributed to the high energy gamma rays emitted during the procedure, the amount of radioactivity administered and the longer time durations of radiation exposure $[51,58,59]$.

The comparison of AAED values received by the occupationally exposed medical workers of Pakistan with other countries is presented in Table 3. The AAED (Table 3, column 3) for all medical occupational workers in Pakistan was 1.06 $\mathrm{mSv}$, as calculated by Equation 2. This indicates that radiation exposure to medical occupational workers is well below the annual dose limit. The AAED data for other countries demonstrate large variations, with the minimum/maximum AAED values of $0.30 / 4.36 \mathrm{mSv}$ reported for the workers of Poland/Chile. These variations in AAED may be attributed to several factors, including the data recording procedure in the national database, the range of procedures performed by the medical worker and the variability in protective measures in different countries, among others. For instance, the criteria for monitored workers differ considerably from country to country. Specifically, the national database of some countries only registers the exposed workers while dropping the non-exposed workers, based on the MDL of the dosimeters used. More specifically, the workers receiving radiation doses below the MDL of the dosimeter used; the dose recorded in the national database may be zero (as is the case in Argentina, Brazil, Canada, India, etc.), a pre-designated level (e.g., for China, Kuwait, and Poland the pre-designated value is $0.015,0.1$ and $0.25 \mathrm{mSv}$, respectively) or the MDL itself (e.g., in Pakistan, Cuba, Indonesia, etc.) [35,60]. Such practices potentially enable misleading conclusions when attempting to compare the AAED values of different countries.

Table 3. Comparison of AAED values for occupationally exposed medical workers of Pakistan with other countries.

\begin{tabular}{cccc}
\hline \hline Country & Study Duration & AAED $(\mathbf{m S v})$ & Reference \\
\hline Pakistan & $2000-2018$ & 1.06 & This study \\
\hline \multirow{2}{*}{ China } & $1991-1995$ & 1.5 & {$[31]$} \\
& $1996-2000$ & 1.4 & {$[29]$} \\
\hline Ghana & $2000-2009$ & 0.69 & {$[27]$} \\
\hline Ireland & $2001-2005$ & 0.32 & {$[1]$} \\
\hline China & 1999 & 1.30 & {$[47]$} \\
\hline Poland & 1999 & 0.3 & {$[20]$} \\
\hline \multirow{2}{*}{ Turkey } & $1995-1999$ & 0.38 & {$[19]$} \\
\hline Argentina & $2000-2002$ & 2.22 & {$[60]$} \\
\hline Greece & $2000-2002$ & 2.28 & {$[60]$} \\
\hline Canada & $2000-2002$ & 1.16 & {$[60]$} \\
\hline Slovenia & $2000-2002$ & 0.44 & {$[60]$} \\
\hline Romania & $2000-2002$ & 0.89 & {$[60]$} \\
\hline Lithuania & $2000-2002$ & 2.63 & {$[60]$} \\
\hline Spain & $2000-2002$ & 0.79 & {$[60]$} \\
\hline Japan & $2000-2002$ & 1.33 & {$[60]$} \\
\hline Chile & $2000-2002$ & 4.36 & {$[60]$} \\
\hline Worldwide & $1990-1994$ & 1.39 & {$[60]$} \\
\hline \hline
\end{tabular}

\section{Conclusion}

In this review, whole body occupational radiation exposure of Pakistani medical workers has been discussed. In particular, analysis of the online literature demonstrated that the AAED values ranged from 0.66 to $7.37 \mathrm{mSv}$, with the highest occupational radiation dose received by the workers engaged in ${ }^{18}$ FDG PET studies, followed by NM and DR. Moreover, $\sim 98 \%$ of the medical workers received an annual dose below 5 $\mathrm{mSv}$, indicating that the radiation protection and safety protocols are adequate and appropriately implemented. A small fraction of the workers $(n=18 ; 0.07 \%)$ received doses above the annual dose limit of $20 \mathrm{mSv}$. This study will not only facilitate a cross-platform comparison of our personal dosimetry patterns but also stage a ready reference for monitoring and improving radiation protection practices in the country. 


\section{References}

[1] Yuan T, Liang Z, Yongjian J. Dose level of occupational expo-sure in China. Radiat Prot Dosimetry. 2008;128(4):491-495.

[2] Jabeen A, Munir M, Khalil A, et al. Occupational exposure from external radiation used in medical practices in Pakistan by film badge dosimetry. Radiat Prot Dosimetry. 2010;140(4):396-401.

[3] Motevalli SM, Borhanazad AM. Assessment of occupational exposure in medical practice in Tehran, Iran. Rom Reports Phys. 2015;67(2):431-438.

[4] Wakeford R. Radiation in the workplace - a review of studies of the risks of occupational exposure to ionising radiation. J Radiol Prot. 2009;29:A61-79.

[5] Ali NM. Evolution of Radiation Protection Trends - the Malaysian Perspective. Prog Nucl Sci Technol. 2011;1:14-19.

[6] Muhogora WE, Byorushengo E, Lema US, et al. Occupational radiation exposure in Tanzania (1996-2010): status and trends. Radiat Prot Dosimetry. 2012;153(4):403-410.

[7] Rahman MS, Begum A, Hoque A, et al. Assessment of whole-body occupational radiation exposures in nuclear medicine practices of Bangladesh during 2010-2014. Iran J Nucl Med. 2016;24(1):51-58.

[8] Rahman MS, Begum A, Hoque A, et al. Assessment of whole-body occupational radiation exposure in industrial radiography practices in Bangladesh during 2010-2014. Brazilian J Radiat Sci. 2016;4(2):1-17.

[9] Linet MS, Kim KP, Miller DL, et al. Historical review of occupational exposures and cancer risks in medical radiation workers. Radiat Res. 2010;174(6):793-808.

[10] Pakistan Nuclear Regulatory Authority (PNRA). Regulations on Radiation Protection (PAK/904). 2004.

[11] International Atomic Energy Agency (IAEA). International Basic Safety Standards for protection against ionizing radiation and for the safety of radiation sources, Safety Series No. 115. 1996.

[12] International Atomic Energy Agency (IAEA). Assessment of Occupational Exposure Due to External Sources of Radiation, Safety Guide No. RS-G-1.3. 1999.

[13] International Atomic Energy Agency (IAEA). Occupational Radiation Protection, Safety Guide No. RS-G-1.1. 1999.

[14] International Atomic Energy Agency (IAEA). Occupational Radiation Protection in the Mining and Processing of Raw Materials, Safety Standards Series No. RS-G-1.6. 2004.

[15] International Atomic Energy Agency (IAEA). Radiation Protection and Safety of Radiation Sources: International Basic Safety Standards (GSR Part 3). 2014.

[16] International Commission on Radiological Protection (ICRP). 1990 Recommendations of the International Commission on Radiological Protection. Ann ICRP. 1991;21(1-3).

[17] International Commission on Radiological Protection (ICRP). The 2007 Recommendations of the International Commission on Radiological Protectiin: ICRP Publication 103. Ann ICRP. 2007;37:1-332.

[18] Khan SH, Ahmad SM. Whole Body Dose to Radiation Workers at a Tertiary Care Hospital in Kashmir: Analysis and Comparison with Naional Multi-Institutional Pool of Medical Radiation Workers. Indian J Nucl Med. 2003;18(3):57-61.

[19] Zeyrek CT, Gunduz H. Occupational exposure to ionizing radiation with thermoluminescence dosimetry system in Turkey, in 2003. Radiat Prot Dosimetry. 2005;113(4):374-380.

[20] Gunduz H, Zeyrek CT, Aksu L, Isak S. Occupational exposure to ionizing radiation in the region of Anatolia, Turkey for the period 1995-1999. Radiat Prot Dosimetry. 2004;108(4):293-301.

[21] Samerdokiene V, Atkocius V, Ofomala R. Radiation exposure recieved by the medical radiation workers in Lithuania at the institute of oncology, Vilnius university, 2004-2011. Radiat Prot Dosimetry. 2013;157(1):152-157.

[22] Valuckas KP, Atkocius V, Samerdokiene V. Occupational exposure of medical radiation workers in Lithuania, 1991-2003. Acta Medica Litu. 2007;14(3):155-159.

[23] Samerdokiene V, Atkocius V, Kurtinaitis J, Valuckas KP. Occupational exposure of medical radiation workers in Lithuania, 19502003. Radiat Prot Dosimetry. 2008;130(2):239-243.

[24] Park M, Kim G, Ji YH, et al. Trends of the effective dose distribution of occupational exposures in medical and research departments for KIRAMS in Republic of Korea. Radiat Prot Dosimetry. 2014;158(2):241-245.

[25] Korir GK, Wambani JS, Korir IK. Estimation of annual occupational effective doses from external ionising radiation at medical institutions in Kenya. SA J Radiol. 2011;15(4):116-119.

[26] Almasri HY, Kakinohana Y, Yogi T. Occupational radiation monitoring at a large medical center in Japan. Radiol Phys Technol. 2014;7(2):271-276.

[27] Colgan PA, Currivan L, Fenton D. An assessment of annual whole-body occupational radiation exposure in Ireland (1996-2005). Radiat Prot Dosimetry. 2008;128(1):12-20. 
[28] Kamenopoulou V, Drikos G, Dimitriou P. Occupational exposure to ionizing radiation in Greece (1994-1998). Radiat Prot Dosimetry. 2000;91(4):385-389.

[29] Hasford F, Owusu-Banahen J, Amoako JK, et al. Assessment of annual whole-body occupational radiation exposure in medical practice in Ghana (2000-09). Radiat Prot Dosimetry. 2012;149(4):431-437.

[30] Alramlawi SA, Alsaqr AS, Zayat DMA, Galal M. Assessing the occupational radiation doses for medical workers at Cairo university hospital based on job categories. Arab J Nucl Sci Appl. 2015;48(1):40-43.

[31] Weizhang W, Wenyi Z, Ronglin C, Liang'an Z. Occupational exposures of Chinese medical radiation workers in 1986 - 2000. Radiat Prot Dosimetry. 2005;117(4):440-443.

[32] Behroozi H. Occupational exposure and mistakes in the wearing of film badges in computed tomography staff (1990-2009). Radiography. 2014;20(1):33-35.

[33] Basić B, Beganović A, Samek D, et al. Ten years of monitoring the occupational radiation exposure in Bosnia and Herzegovina. Radiat Prot Dosimetry. 2010;139(1):400-402.

[34] Banu H, Alam MN, Chowdhury MI, et al. Assessment of occupational and patient dose from diagnostic and therapeutic radiation exposure using thermoluminescent dosimetry. Health Phys. 1998;74(4):478-480.

[35] UNSCEAR. Sources and Effects of Ionizing Radiation, United Nations Scientific Committee on the Effects of Atomic Radiation UNSCEAR 2000 Report to the General Assembly, with Scientific Annexes [Internet]. Vol. I. 2000. 1-17 p. Available from: http://www.unscear.org/docs/publications/2000/UNSCEAR_2000_Report_Vol.I.pdf

[36] The pakistan atomic energy commission ordinance, 1965. Gazette of Pakistan, No: XVII of 1965.

[37] Hussain M, Khan RA, Nasim B. Regulatory Framework for Occupational Exposure Management in Pakistan. 2009;1-5. Available from: http://www.isoe-network.net/publications/pub-proceedings/symposia/international-symposia/vienna-austria-october2009/papers-5/session-4-occupational-exposure-in-npps-1/1304-nasim2009-pdf/file.html

[38] Fazal-e-Rahim, Shah AS, Rahim I. Trends in occupational radiation exposures at IRNUM (2000-2008). Pakistan J Radiol. 2011;21(2):59-62.

[39] Masood K, Ahmad M, Zafar J, et alH. Assessment of occupational exposure among Pakistani medical staff during $2007-2011$. Australas Phys Eng Sci Med. 2012;35(3):297-300.

[40] Memon SA, Laghari NA, Cheema AA. Evaluation of radiation workers' occupational doses working at NIMRA Jamshoro. J Liaquat Univ Med Heal Sci. 2012;11(3):190-194.

[41] Zafar T, Masood K, Zafar J. Assessment of personal occupational radiation exposures received by nuclear medicine and oncology staff in Punjab (2003-2012). Australas Phys Eng Sci Med. 2015;38(3):473-478.

[42] Younas S, Yar A, Qadir E, Nawaz K. Radiation dose management of ${ }^{18}$ FDG for occupational workers and comforters. Pakistan J Nucl Med. 2015;5(1):58-66.

[43] Gadhi MA, Fatmi S, Gadhi MS, et al. Variation of annual effective dose from external ionizing radiation among radiation workers of Bahawalpur Institute of Nuclear Medicine and Oncology (BINO). Pakistan. Int J Radiat Res. 2016;14(3):229-235.

[44] Razaq A, Waqar M, Soomro Q, Javed MA. Evaluation of radiation workers occupational doses for newly established medical center NORIN Nawabshah in Pakistan. J Med Phys Biophys. 2016;3(1):61-65.

[45] Ahmad M, Ahmad H, Khattak MR, et al. Assessment of Occupational Exposure From External Radiation to Workers at IRNUM , Pakistan (2009-2016). Iran J Med Phys. 2017;14(4):197-202.

[46] Carreiro JV, Avelar R. Occupational exposure in medical and paramedical professions in Portugal. Radiat Prot Dosimetry. 1991;36(2):233-236.

[47] Koczynski A, Chec A, Lach D, Dabek M. Occupational exposure to external ionizing radiation in Poland, 1999. Radiat Prot Dosimetry. 2001;96(1-3):61-62.

[48] El-din MME, Mahmoud RMM, Abaza A, et al. Occupational Radiation Exposure in Pet/Ct Units. Arab J Nucl Sci Appl. 2017;50(3):58-65.

[49] Seierstad T, Stranden E, Bjering K, et al. Doses to nuclear technicians in a dedicated PET/CT centre utilising 18F flurodeoxyglucose (FDG). Radiat Prot Dosimetry. 2007;123(2):246-249.

[50] Roberts FO, Gunawardana DH, Pathmaraj K, et al. Radiation Dose to PET Technologists and Strategies to Lower Occupational Exposure. J Nucl Med Technol. 2005;33(1):44-47.

[51] Antic V, Ciraj-Bjelac O, Stankovic J, et al. Radiation exposure to nuclear medicine staff involved in PET/CT practice in Serbia. Radiat Prot Dosimetry. 2014;162(4):577-585.

[52] Castrillo SV, Henriquez FC. A study on occupational exposure in a PET/CT facility. Radiat Prot Dosimetry. 2011;147(1):247-249.

[53] Dalianis K, Kollias G, Malamitsi J, et al. Doses to medical workers operating in a PET/CT department after the use of new dynamic techniques. J Phys Conf Ser. 2015;637(1):12003. 
[54] Demir M, Demir B, Yaşar D, et al. Radiation doses to technologists working with 18 F-FDG in a PET center with high patient capacity. Nukleonika. 2010;55(1):107-112.

[55] Cronin B, Marsden PK, Doherty MJO. Are restrictions to behaviour of patients required following fluorine-18 fluorodeoxyglucose positron emission tomographic studies ? Eur J Nucl Med. 1999;26(2):121-128.

[56] Biran T, Weininger J, Malchi S, et al. Measurement of occupational exposure for 18F FDG PET scans. Health Phys. 2004;87(5):539544.

[57] Zeff BW, Yester M V. Patient self-attenuation and technologist dose in positron emission tomography. Med Phys. 2005;32(4):861865.

[58] Benator NA, Cronin BF, O’Doherty MJ. Radiation dose rates from patients undergoing PET: Implications for technologists and waiting areas. Eur J Nucl Med. 2000;27(5):583-589.

[59] Chiesa C, Sanctis V De, Crippa F, et al. Radiation dose to technicians per nuclear medicine procedure: comparison between technetium-99m, gallium-67, and iodine-131 radiotracers and fluorine-18 fluorodeoxyglucose. Eur J Nucl Med. 1997;24(11):13801389.

[60] UNSCEAR. Sources and Effects of Ionizing Radiation, United Nations Scientific Committee on the Effects of Atomic Radiation UNSCEAR 2008 Report to the General Assembly, with Scientific Annexes. Vol. I. 2008. 1-683 p. 